\title{
REDARTE-SP: integrando recursos de informação em arte da cidade de São Paulo'
}

Maria Christina Barbosa de Almeida

Doutora em Ciência da Informação pela ECA. Especialista em Administração Pública pela FGV/EAESP.

Docente do Departamento de Biblioteconomia da ECA/USP e coordenadora da Rede de Informação em Arte da cidade de São Paulo (REDARTE/SP).

Autora do livro Planejamento de bibliotecas e serviços de informaçãoº, idealizadora e coordenadora das duas primeiras edições do Guia de museus brasileiros ${ }^{3}$.

E-mail: mcbdalme@usp.br

Paulo Simões de Almeida Pina

Bacharel em Biblioteconomia e Documentação pela ECA-USP e especialista em Gestão Cultural pela Universidade de Paris III - Sorbonne Nouvelle.

Bibliotecário da Biblioteca Jenny Klabin Segall do Museu Lasar Segall/IPHAN/MinC $e$ do Goethe-Institut São Paulo.

Membro da Rede de Informação em Arte da cidade de São Paulo (REDARTE/SP).

E-mail: pspina@mls.gov.br

A REDARTE/SP é uma rede de serviços de informação em arte localizada na cidade de São Paulo. É constituída tanto de equipamentos culturais e educacionais - bibliotecas, centros de documentação, centros de referência, arquivos, centros de pesquisa, setores de museus etc. -, quanto de espaços virtuais de informação ou projetos vinculados a instituições públicas ou privadas.

Conhecer a complexidade da cidade de São Paulo é fundamental para uma reflexão sobre a função dos profissionais de informação de arte e das instituições da área. São Paulo, que já completou mais de 450 anos, é, com seus 10,6 milhões de habitantes, a maior cidade brasileira e da América do Sul, sendo considerada também o quarto maior aglomerado urbano no mundo, já que sua região metropolitana possui uma população de cerca de 18 milhões de pessoas. É um importante centro econômico, com alta concentração de instituições financeiras e empresas, sobretudo de serviços. Possui ampla e diversificada infra-estrutura turística e de eventos, com quase 12,5 mil restaurantes, $15 \mathrm{mil}$ bares e centenas de danceterias, casas de shows e grandes hotéis (sem contar a terceira maior frota de helicópteros do mundo!).

1. Uma primeira versão deste trabalho foi apresentada no Congresso Internacional da Ifla - International Federation of Library Associations, Buenos Aires, em agosto de 2004 e, posteriormente, publicada na revista Art Libraries Journal, London, v. 30 , n. 3 , p. 20-24, 2005.

2. ALMEIDA, Maria Christina Barbosa de. Planejamento de bibliotecas e serviços de informação. Brasília: Briquet de Lemos, 2005.

3. Id. (Org.). Guia de museus brasileiros. São Paulo: USP/CPC, 1997. 
4. Esses dados são aproximados, pois ainda não existe uma pesquisa sistemática de indicadores culturais no Brasil. Fonte: Fundação SEADE, 2002.

5. Taxas de analfabetismo, por sexo, segundo grupos de idade e raça/cor do município de São Paulo. Faixa: 15 anos e mais 2000. Fundação SEADE. Fonte: IBGE, 2000.

6. Taxa de evasão escolar de ensino fundamental total, 2002. Fonte: Fundação SEADE, 2004
Com intensa vida cultural, reúne perto de 300 salas de cinema, 120 teatros, 70 museus, 45 centros culturais, além de salas de exposições e galerias ${ }^{4}$. São inúmeras as escolas de arte e os cursos livres e oficinas, a maioria com grande demanda. Exposições de arte itinerantes, festivais de música, cinema, vídeo, teatro e dança são muito freqüentes e geralmente atraem público numeroso, bem como feiras, seminários e congressos nas áreas de cultura.

Apesar de sua pujança econômica, a cidade de São Paulo apresenta acentuado quadro de desigualdades e de exclusão social, o que se reflete nos indicadores de renda, trabalho, saúde, educação e habitação, especialmente nas áreas periféricas.

Em relação à educação, embora a cidade tenha grande número de estudantes - mais de 2 milhões de alunos matriculados nos ensinos fundamental e médio e cerca de 400 mil no ensino superior $(10,85 \%$ do total de alunos de graduação do país) -, ainda mostra altas taxas de analfabetismo $(4,9 \%)^{5}$ e de evasão escolar $(2,03 \%)^{6}$, além da constante luta pela melhoria da qualidade na educação.

Toda essa complexa malha social traz enorme dificuldade para o trabalho na área cultural, especialmente em bibliotecas e centros de informação, em função da diversidade dos públicos abrangidos por esses serviços e da valorização da cultura de eventos em detrimento do desenvolvimento e da manutenção adequada dos espaços culturais e serviços, e da preservação e dinamização das coleções.

Os altos níveis de exclusão social coincidem com os de exclusão cultural, que, por sua vez, está relacionada aos crescentes índices de violência. A inexistência de políticas públicas eficazes, principalmente voltadas para o enfrentamento dessas questões no âmbito cultural, colabora para a continuidade do problema. Essas políticas exigiriam uma ação cultural descentralizada, que garantisse o acesso à produção e ao consumo de bens culturais e à informação sobre arte nas áreas periféricas da cidade, onde se têm desenvolvido movimentos culturais comunitários.

Dessa forma, o trabalho com informação em arte constitui grande desafio, na medida em que, ao lado daquele voltado ao público especializado, pode auxiliar na educação estética e artística da população menos favorecida, contribuir para o desenvolvimento da sensibilidade e do gosto e estimular tanto o fazer artístico quanto a formação de público para as artes. Especialmente às crianças e adolescentes, aos desempregados, idosos (cuja taxa de crescimento vem aumentando ano a ano) e à população de baixa renda, a inclusão cultural é uma forma de fortalecer a auto-estima e a cidadania.

São, assim, inúmeras as funções sociais que os serviços de informação em arte podem desempenhar na cidade de São Paulo, além do atendimento aos diferentes públicos especializados - pesquisadores e profissionais que trabalham diretamente com as artes - e ao público em geral interessado em adquirir maiores conhecimentos sobre arte.

Embora não tenhamos realizado um mapeamento exaustivo dos serviços de informação em arte da cidade, estimamos que cheguem a mais de cinco dezenas. 
Um dos traços relevantes desses serviços consiste na sua heterogeneidade, tanto em relação às organizações que os mantêm e a suas finalidades, quanto aos assuntos tratados e à variedade de materiais de seus acervos. Ademais, esses serviços apresentam públicos diversificados - refletindo a morfologia da cidade - e encontram-se em diferentes estágios de desenvolvimento, em que sistemas mais simples de informação convivem com os mais sofisticados, de gerenciamento complexo e alto custo.

\section{ANTECEDENTES - ANOS 1970}

A REDARTE/SP foi formada em julho de 1998, mas os primeiros projetos em cooperação iniciaram-se nos anos 1970. Não se pode afirmar que eram projetos de um grupo, pois, geralmente, envolviam equipes de bibliotecas de duas instituições afins, destacando-se como protagonistas, naquele período, a Biblioteca da Escola de Comunicações e Artes da Universidade de São Paulo e a Biblioteca Jenny Klabin Segall do Museu Lasar Segall. Outros projetos com organizações da sociedade civil, tais como a Sociedade Brasileira de Música Contemporânea, a Associação Paulista de Teatro Infanto-Juvenil, entre outras, também se concretizaram nesse período e contribuíram para o desenvolvimento de atividades de documentação especializada, a qual, além de qualificar o trabalho das bibliotecas e ampliar seu acervo, propiciou o aprimoramento profissional especializado dos bibliotecários.

Nesse período, em que não se falava, ainda, em microcomputador, nem se sonhava com a internet e nenhuma biblioteca de arte era informatizada, o acesso à informação sobre os acervos e o material publicado era muito difícil, já que dependia de telefonemas e de visitas às bibliotecas. Se essa situação, por um lado, dificultava o trabalho de pesquisa dos usuários, por outro, constituiu um estímulo para os bibliotecários preocupados com o acesso. Dos projetos dessa época resultaram, sobretudo, publicações tais como a Bibliografia da dramaturgia brasileira ${ }^{7}$, o Guia de corais brasileiros ${ }^{8}$ e os Catálogos de compositores brasileiros $^{9}$, para citar alguns.

\section{ANOS 1980}

O primeiro diagnóstico dos serviços de informação em arte da cidade de São Paulo foi desenvolvido em 1985 e atualizado em 1988. Esse diagnóstico, que envolveu dezoito instituições da cidade, identificou os seguintes pontos frágeis e comuns no conjunto dessas bibliotecas:

- falta de diretrizes na formação das coleções - não havia políticas integradas que definissem a vocação de cada serviço de informação;

- dispersão e desatualização do acervo - visto como um todo, o acervo disponível nas bibliotecas de arte da cidade era, aparentemente, muito rico; no entanto, observado isoladamente, mostrou-se desatualizado, fragmentado, descaracterizado e pouco representativo;
7. UNIVERSIDADE de São Paulo. Bibliografia da dramaturgia brasileira. São Paulo: ECA-USP/Museu Lasar Segall, 1981.

8. UNIVERSIDADE de São Paulo. Guia de corais brasileiros. São Paulo: ECA-USP/Federação Paulista de Conjuntos Corais, 1981.

9. UNIVERSIDADE de São Paulo. Catálogos de compositores brasileiros. São Paulo: ECA/USP; Brasília: MRE, 1981. 
- ausência de racionalização de procedimentos técnicos;

- necessidade de modernização do trabalho pela adoção de novos enfoques profissionais e utilização de tecnologias inovadoras;

- insuficiência de recursos humanos.

Esses aspectos são todos interdependentes, pois, além da carência de recursos financeiros para o desenvolvimento adequado dos acervos, a dificuldade de acesso aos documentos era agravada pelas inúmeras obras não catalogadas ou pelo processamento técnico inadequado. A crônica falta de recursos humanos, a inexistência de programas informatizados e de um serviço cooperativo na área, bem como a ausência de formação especializada do bibliotecário e de instrumentos de apoio ao trabalho de tratamento da informação, como thesauri e vocabulários controlados em língua portuguesa, nas várias áreas, dificultavam o desenvolvimento de um trabalho qualitativo e o acesso à informação.

Os documentos audiovisuais e a diversidade de suportes documentários normalmente encontrados nas bibliotecas de arte acentuaram ainda mais o problema do acesso às coleções, por exigirem processamento técnico e armazenamento especiais, os quais dependiam de recursos humanos capacitados e de meios físicos e materiais que garantissem as condições mínimas de arquivamento das coleções.

Além dessas questões, alguns dos serviços de informação encontravam-se estreitamente vinculados às instituições que os abrigavam, estando os acervos e as atividades integrados aos seus projetos. Outros, no entanto, eram organismos totalmente desvinculados dos objetivos das instituições de que faziam parte: os acervos não eram pertinentes às áreas de interesse dessas instituições, os serviços não estavam integrados às linhas de trabalho ou às prioridades destas e os horários de funcionamento eram inadequados; por essas razões, seu público - quando possuíam - não freqüentava outros espaços da instituição, nem pertencia a seu quadro funcional. Com tal configuração, esses serviços constituíam espaços paralelos, isolados, o que contribuiu para, dentro da política velada das instituições, serem geralmente tratados como dispensáveis, supérfluos.

O diagnóstico também apontou que os bibliotecários de arte não estavam organizados - a exemplo dos de outras áreas ou de outros setores - em grupos de trabalho interbibliotecas, destinados à discussão de problemas comuns e à busca de soluções integradas. Trabalhavam de forma isolada e raramente conheciam os profissionais de outras instituições, a abrangência de seu acervo e seus produtos.

Nesse cenário, não é difícil avaliar o árduo caminho que precisava percorrer quem buscasse uma informação ou um documento específico; busca em vão, inclusive, devido à não-existência do documento na cidade, ao desconhecimento de sua existência por falta de registro ou de divulgação, ou - caso existisse - à falta de acesso, pela impossibilidade de empréstimo ou dificuldade de consulta.

Havia uma ampla faixa de usuários de documentos atinentes às artes - o estudante, o professor, o pesquisador, o agente cultural, o profissional de cada uma das áreas e outras pessoas interessadas sem formação adstrita à área -, 
ou seja, existia, potencialmente, uma ampla gama de demanda. No entanto, a maioria das bibliotecas era subutilizada.

Esforços isolados de algumas instituições, em 1970 e 1980, foram relevantes, mas insuficientes para transformar o estado geral de precariedade da informação e da documentação na área. Por essa razão, em 1988 foi apresentado ao Instituto Cultural Itaú - ICI ${ }^{10}$ um programa que previa a implantação de certa rede automatizada de informações, com o objetivo de possibilitar o acesso dos interessados a quaisquer tipos de documentos referentes às áreas de artes localizados nas bibliotecas participantes da rede. Para a recuperação temática dos documentos, um grupo de bibliotecários e especialistas elaborou o Vocabulário Controlado de Arte, iniciativa pioneira numa área em que, até então, no Brasil, nada havia sido feito. Colaboraram nessa iniciativa, sob a coordenação de Maria Christina Barbosa de Almeida, bibliotecários e profissionais atuantes em serviços de informação em arte na cidade de São Paulo, dentre os quais destacamos Elza Barbosa, Ivani Di Grazia Costa, Isabel Christina Filgueiras de Almeida, Maria Ângela Marques, Maria Cecília Soubhia, Leda Amélia Bicalho, Márcia Ippolito Bueno de Camargo, Mónica Aliseres, Maria Rita Lana e Muriel Scott. O grupo contou, também, com a colaboração eventual de pesquisadores de arte e especialistas.

\section{ANOS 1990}

Nos anos 1990, não se verificaram grandes mudanças no conjunto dos serviços de informação em relação ao quadro analisado na década anterior. No entanto, muitas instituições desenvolveram-se, foram informatizadas e tiveram condições de prestar um serviço de ponta e de liderar esforços cooperativos, a única saída para um salto qualitativo na área.

Algumas bibliotecas começaram a promover iniciativas conjuntas, constituindo ferramentas valiosas para assegurar a qualidade da representação temática dos documentos nesse campo. As primeiras iniciativas voltadas ao desenvolvimento de uma terminologia no âmbito de cinema datam dos anos 1980, quando bibliotecárias da Cinemateca Brasileira e do Museu Lasar Segall - Elenice de Castro e Maria Cecília Soubhia - traduziram a lista de cabeçalhos de assunto da FIAF - Federação Internacional de Arquivos de Filmes. Nos anos 1990, como extensão do Vocabulário Controlado de Arte, foi iniciada a construção do Vocabulário Controlado de Cinema, com a participação de Jair Piantino e Maria Christina Barbosa de Almeida, pela Fundação Cinemateca Brasileira, e de Amélia Maria Moreira e Maria Cecília Soubhia, pelo Museu Lasar Segall; contou ainda com a colaboração do Itaú Cultural - na época, Instituto Cultural Itaú - para a digitação dos dados. Profissionais de outras instituições, tais como da Divisão de Processos Técnicos do Departamento de Bibliotecas Públicas e da Divisão de Pesquisas do Centro Cultural São Paulo - IDART, auxiliaram no aprimoramento e ampliação deste vocabulário e no desenvolvimento do vocabulário controlado em artes cênicas, que resultou no Vocabulário Controlado em Artes do Espetáculo, coordenado por Maria Cecília Soubhia.

10. Atualmente denominado Instituto Itaú Cultural. 
No entanto, havia muito a ser feito: era preciso ampliar benefícios, tanto em qualidade de acervo, serviços e produtos quanto em quantidade - pelo aumento da oferta de informação e pela ampliação e diversificação de seu público.

Bibliotecas, arquivos e centros de documentação estavam ainda muito distantes do dia-a-dia dos profissionais das artes - com possível exceção dos pesquisadores, historiadores e críticos que, por força de suas funções, devem incansavelmente buscar informação e descobrir documentos. Grande parte da informação existente nas bibliotecas de arte, nos centros de documentação e nos arquivos especializados era subtilizada porque, na prática, estava inacessível a seu usuário.

Essa situação foi verificada, particularmente, na área de artes visuais, que se tornou objeto de um estudo de caso, no período compreendido entre 1995 e 1997, e forneceu subsídios a uma tese ${ }^{11}$ de doutoramento apresentada à Universidade de São Paulo, a qual serviu de estímulo à formação da REDARTE/SP.

\section{A ATUAÇÃO DA REDARTE/SP}

A situação encontrada na cidade exigia a definição de uma estratégia global para as bibliotecas e os serviços de documentação da arte. A partir da criação de uma rede articulada, era preciso favorecer o surgimento de projetos cooperativos que possibilitassem o aproveitamento compartilhado ou integrado dos recursos - desenvolvendo ações relacionadas à documentação da arte e sobre arte - e a comunicação entre os membros dessas redes; e, ainda, a interligação com outros sistemas e redes ou bases de dados externos, acompanhando a tendência internacional de ganhos de escala em termos de trabalho com informação.

Esse era o propósito inicial da REDARTE/SP, cuja força repousa, sobretudo, na vontade de trabalhar com uma orientação comum. Para tanto, foi preciso pensar uma organização na forma de rede de serviços, a qual remediasse as divisões institucionais vigentes, agrupadas em serviços de informação por tipo ou fonte de recursos, mas que na realidade os separam de outros serviços de mesma natureza. Por outro lado, um programa com tal abrangência não poderia envolver, naturalmente, apenas o bibliotecário de arte, mas todos os profissionais atuantes na área de informação de arte e especialistas. Tornava-se, pois, indispensável desenvolver uma estratégia de comunicação que minimizasse as barreiras entre os diversos profissionais responsáveis por serviços de informação e por coleções - museólogos, arquivistas, bibliotecários - e os pesquisadores e especialistas.

Quanto ao público ligado à informação da arte, muito amplo e diversificado,

11. ALMEIDA, Maria Christina Barbosa de. Por uma rearquitetura dos serviços de informação em arte na cidade de São Paulo. 1998. Tese (Doutorado em Ciência da Informação)-Escola de Comunicações e Artes, Universidade de São Paulo, São Paulo, 1998 é preciso elaborar estudos que ajudem a definir a importância da biblioteca e dos centros de documentação em sua atividade profissional, a identificar bibliotecas/centros de documentação utilizados, bem como suas fontes de informação; é necessário saber, enfim, como trabalham e usam os serviços de informação estruturados e as novas tecnologias, além de colher sugestões sobre a questão da documentação da arte e o papel que devem desempenhar as bibliotecas e os serviços de informação da arte hoje, em nosso meio. 
Devemos nos ocupar também do não-público, usuário em potencial da documentação artística, priorizando-se, aqui, os profissionais da área que não freqüentam serviços de informação.

Entretanto, não podemos deixar de lado o público não-especializado - o estudante, o professor, o pesquisador, o agente cultural ou qualquer pessoa interessada nas várias modalidades de arte -, que também constitui uma faixa considerável da demanda potencial.

Ampliar o acesso do público à informação sobre arte é também uma forma de criar novos públicos, favorecendo a compreensão e a atividade artística, estimulando a criação e a pesquisa na área, bem como fornecendo elementos para sua apreciação. Formar o apreciador de arte é, justamente, dar elementos para que possa se apropriar dos bens culturais, numa tentativa de combater a privação imposta pela instrução deficiente e origem social. Essa apropriação inicia-se mediante o domínio do código. E isso se pode aprender. A informação artística tem, portanto, um papel a desempenhar no desenvolvimento da competência artística dos indivíduos e na formação de público para as artes. As instituições que cuidam da informação e da documentação da arte devem assumir também essa tarefa.

Considerando que os recursos financeiros são sempre insuficientes - e quase inexistentes, em épocas de crise econômica -, não se pode dispersar meios e esforços com projetos inviáveis, inadequados ou inúteis, ou que, isolados, mesmo que tenham qualidade, nunca poderão cobrir as necessidades informacionais da área, mostrando-se, rigorosamente, ineficazes.

A REDARTE/SP pretende atuar por meio de projetos interinstitucionais que priorizem formas de gerenciamento integrado da informação e, ao mesmo tempo, contemplem as prioridades da instituição e as necessidades da área, no âmbito da cidade, evitando a dispersão de recursos, a fragmentação de acervos e a duplicação de serviços; têm de promover, concomitantemente, a circulação e a ampla divulgação da informação sobre arte, em particular sobre arte brasileira.

No momento, a REDARTE/SP concentra-se na estratégia de divulgação. Desenvolveu um projeto de comunicação que inclui a criação de um site - um portal dedicado às artes, principalmente à arte brasileira - e um guia das bibliotecas e serviços de informação da cidade, e está empenhada na captação de recursos para viabilizar esse projeto $^{12}$.

Em paralelo, está elaborando sua política de atuação, o que pressupõe a definição de foco e de prioridades, levando em conta a análise de contexto e dos pontos fortes dos atuais participantes. O processo de escolha do foco desenvolve-se a partir dos diferentes eixos especificados a seguir, ou da combinação deles:

- a linguagem artística ou forma de expressão - artes cênicas, artes plásticas, cinema, fotografia, música etc.;

- o suporte documental - impressos, audiovisuais, digitais etc.;

- os processos que integram a gestão de informação e de acervos - aquisição, conservação preventiva de coleções, documentação, tratamento e disseminação da informação;

- produtos - fontes de informação sobre arte brasileira, tais como bibliografias, filmografias e discografias, inventários de arquivos especializados etc.
12. Uma primeira versão do site, desenvolvida com o apoio do Goethe - Institut São Paulo, foi disponibilizada em outubro de 2005 : <http://www.goethe.de/ ins/br/sap/prj/red/ptindex. htm>. 
A decisão sobre o foco de atuação para o próximo ano orientará o planejamento e as ações do grupo, mas o sucesso da REDARTE/SP depende, sobretudo, do compromisso dos profissionais participantes em desenvolver um trabalho sem restrições pessoais ou corporativas e do reconhecimento dessas ações.

São amplas as possibilidades de atuação no Brasil, um contexto em que ainda há muito a ser feito. Pretende-se que a articulação em rede dos serviços de informação em arte da cidade de São Paulo - concomitantemente ao trabalho desenvolvido, desde 1995, na cidade do Rio de Janeiro - traga melhor organização da informação na área e maior acessibilidade, favorecendo o atendimento de uma demanda que também será ampliada em função da disponibilidade da informação organizada e de sua maior divulgação e circulação. Da mesma forma, acredita-se que a REDARTE/SP, ao auxiliar a troca de informações e experiências entre os diversos profissionais, contribui para seu desenvolvimento permanente e para a formação de lideranças na área que, compartilhando visões, ajudem a transformar a situação diagnosticada em São Paulo e, em articulação com outros atores, colaborem para a redução da exclusão cultural na cidade.

Finalmente, a visibilidade que o trabalho em rede pode trazer certamente será benéfica para sua credibilidade tanto por parte das organizações mantenedoras desses serviços quanto do público.

Resumo: A REDARTE/SP, criada em 1998, é uma rede de serviços de informação em arte localizada na cidade de São Paulo, que inclui bibliotecas, centros de documentação, centros de referência, arquivos, centros de pesquisa, setores de museus e outras organizações públicas ou privadas responsáveis por projetos ou espaços virtuais. Pretende-se que a articulação em rede dos serviços de informação em arte da cidade de São Paulo possibilite 0 desenvolvimento de projetos conjuntos, a organização mais eficiente da informação na área e maior acessibilidade, favorecendo o atendimento de uma demanda que também será ampliada em função da disponibilidade da informação organizada e de sua maior divulgação e circulação. Além disso, a REDARTE/SP, ao favorecer a troca de informações e experiências entre diversos profissionais, deverá contribuir para seu desenvolvimento permanente e para a formação de lideranças na área que, compartilhando visões, ajudem a transformar a situação diagnosticada em São Paulo e, em articulação com outros atores, colaborem para a redução da exclusão cultural na cidade.

Palavras-chave: rede de informação em arte, bibliotecas de arte, serviços de informação em arte, São Paulo.
Abstract: Art information providers in the city of Sao Paulo, Brazil, include libraries, archives, and documentation sections in art museums and cultural centers. In 1998 a network of these services in that city, REDARTE-SP, was created to facilitate discussion of theoretical, technical and organizational issues facing art information services and to formulate collaborative projects. The subsequent exchanging of ideas, discussion of successful practices and development of shared projects empowers art information professionals, contributes to improving the quality of art information services and products, provides better use of the available resources and widens the circle of users.

Keywords: art information network, art libraries, art documentation, art archives, São Paulo. 